\title{
A determination of emergency department pre-triage times in patients not arriving by ambulance compared to widely used guideline recommendations - CORRIGENDUM
}

M. Betz, J. Stempien, S. Trivedi, R. Bryce

doi: $10.1017 /$ cem.2016.398

In the original publication of "A determination of emergency department pre-triage times in patients not arriving by ambulance compared to widely used guideline recommendations," author Sachin Trivedi's last name was misspelled.

The authors and editors regret this error, and the original has since been updated.

\section{REFERENCE}

Betz M, Stempien J, Trivedi S, Bryce R. A determination of emergency department pre-triage times in patients not arriving by ambulance compared to widely used guideline recommendations. CFEM 2016; epub, doi:10.1017/cem.2016.398.

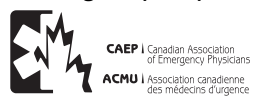

